\title{
Diagnosing Heart Disease using Wavelet Transformation and Adaptive Neuro Fuzzy Inference System (ANFIS) Based on Electrocardiagram (ECG)
}

\section{Diagnosa Penyakit Jantung dengan Transformasi Wavelet dan Adaptive Neuro Fuzzy Inference System (ANFIS) Berdasarkan Data Elektrokardiogram (EKG)}

\author{
Indah Puspita ${ }^{*}$, Agus Maman Abadi \\ Program Studi Matematika, FMIPA Universitas Negeri Yogyakarta, Yogyakarta, \\ 55281, Telp (0274)550846 \\ *iindaah.puspita@gmail.com
}

\begin{abstract}
Heart disease is the leading cause of death in the world. Heart disease is called the silent killer, because it often occcurs suddenly. Therefore, periodic cardiac examination is very necessary to reduce cases of death from heart disease.Heart disease can be known through electrocardiogram (ECG) examination. This study aims to explain the process of diagnosing heart disease through ECG using wavelet transformation and Adaptive Neuro Fuzzy Inference System (ANFIS).
\end{abstract}

The process of diagnosing heart disease begins with cutting ECG signal consisting of 911 waves into one ECG wave, then decomposition and extraction are performed using wavelet transformation to obtain 6 parameters. The parameters will be used as input in ANFIS model. Data obtained from ECG extraction are divided into $70 \%$ training data and 30\% testing data The output from the ANFIS model is a diagnosis of heart diseases, such as left bundle branch block (LBBB), right bundle branch block (RBBB), and normal. ANFIS learning is divided into 6 stages, namely clustering data with Fuzzy $C$ Means method, computing the degree of membership of each data, determining fixed neurons, looking for normalized firing strength, calculating the consequent parameter values, and determining network output.

The results of the study obtained the best ANFIS model with 10 clusters. The level of accuracy, specificity, and sensitivity for training data is 100\%, 100\%, and 100\%, respectively and for the testing data, the level of accuracy, specificity, and sensitivity is $100 \%, 100 \%$, and 100\%, respectively.

Keywords: Heart Disease, Wavelet Transformation, Adaptive Neuro Fuzzy Inference System (ANFIS).

\footnotetext{
Abstrak

Penyakit jantung merupakan penyebab kematian nomor satu di dunia. Penyakit jantung disebut sebagai silent killer karena seringkali terjadi secara tiba-tiba. Oleh karena itu, pemeriksaan jantung secara berkala sangat diperlukan untuk mengurangi kasus kematian akibat penyakit jantung.Penyakit jantung dapat diketahui lewat pemeriksaan elektrokardiagram (EKG). Penelitian ini bertujuan untuk menjelaskan proses diagnosa 
penyakit jantung melalui rekaman EKG menggunakan transformasi wavelet dan Adaptive Neuro Fuzzy Inference System (ANFIS).

Proses diagnosa penyakit jantung diawali dengan pemotongan rekaman sinyal EKG yang terdiri dari 9-11 gelombang menjadi satu gelombang utuh EKG. Selanjutnya, dilakukan dekomposisi dan ekstraksi menggunakan transformasi wavelet untuk memperoleh 6 parameter. Parameter yang telah diperoleh akan digunakan sebagai input pada proses pembentukan model ANFIS. Data yang diperoleh dari hasil ekstraksi EKG dibagi menjadi $70 \%$ data latih dan $30 \%$ data uji. Output yang diperoleh dari model ANFIS adalah hasil diagnosa penyakit jantung, yaitu normal, left bundle branch block (LBBB), dan right bundle branch block (RBBB). Pembelajaran ANFIS terbagi menjadi 6 tahapan, yaitu pengelompokan (clustering) data dengan metode Fuzzy C-Means, menentukan derajat keanggotaan setiap data, menentukan neuron tetap, mencari bobot normalized firing strength, menentukan nilai parameter konsekuen, dan menentukan output jaringan.

Hasil penelitian diperoleh model ANFIS terbaik dengan 10 klaster. Tingkat akurasi, spesifitas, dan sensitivitas untuk data latih secara berurutan adalah 100\%, 100\%, dan $100 \%$ dan untuk data uji diperoleh tingkat akurasi, spesifitas, dan sensitivitas adalah $100 \%, 100 \%$, dan $100 \%$.

Kata kunci: Penyakit Jantung, Transformasi wavelet, Adaptive Neuro Fuzzy Inference System (ANFIS)

\section{Pendahuluan}

Penyakit jantung adalah salah satu jenis penyakit tidak menular (PTM). Penyakit ini menjadi penyebab kematian nomor satu di dunia setiap tahunnya. Pada tahun 2008, diperkirakan sebanyak 17,3 juta kematian disebabkan oleh penyakit jantung. Lebih dari 3 juta kematian terjadi sebelum usia 60 tahun dan seharusnya dapat dicegah (Kemenkes, 2014). Pencegahan dini penyakit jantung sangat diperlukan untuk mengurangi angka kematian dini, salah satu caranya adalah dengan menerapkan pola hidup sehat dan melakukan pemeriksaan jantung secara rutin. Salah satu metode dalam dunia kesehatan yang digunakan untuk pemeriksaan jantung adalah Elektrodiagram (EKG). EKG merupakan rekaman aktivitas listrik sel di atrium dan ventrikel jantung. serta membentuk gelombang yang spesifik (Dharma:2009, 7). EKG merekam setiap irama dari aktivitas jantung saat memompa maupun menerima darah yang hasilnya terlihat pada kertas elektrokardiagram dalam bentuk gelombang.

Rekaman EKG yang diperoleh melalui pemeriksaan, kemungkinan mengandung beberapa noise atau derau yang disebabkan oleh kontraksi otot, kesalahan peletakan elektroda, gerakan 
pasien selama pemeriksaan, dan sebagainya. Hal ini menyebabkan perlunya dilakukan processing pada sinyal untuk menghilangkan gangguan tersebut dari sinyal EKG. Salah satu metode yang dapat digunakan adalah transformasi wavelet (Vijayavanan, dkk, 2014).

Transformasi wavelet adalah salah satu metode pemrosesan sinyal digital. Transformasi wavelet dapat digunakan untuk mengekstraksi ciri dari sinyal-sinyal non-stasioner yang memiliki frekuensi berubah-ubah terhadap waktu, seperti pada sinyal EKG. Kelebihan dari analisis sinyal menggunakan transformasi wavelet yaitu dapat menganalisa sinyal pada domain waktu dan frekuensi. Transformasi wavelet juga dapat membantu menghilangkan noise atau gangguan pada sinyal EKG, sehingga dapat memberikan hasil diagnosa yang lebih akurat.

Beberapa peneliti telah melakukan penelitian terhadap EKG menggunakan transformasi wavelet. Vijayavanan,dkk (2014) melakukan klasifikasi sinyal EKG menjadi 2 kelompok yaitu normal dan arrhythmia menggunakan discrete wavelet transform dan klasifikasi dengan probabilistic neural network, diperoleh keakuratan 96,5\%. Penelitian oleh Zadawaledan Bakare (2017) tentang prediksi penyakit jantung melalui sinyal EKG dengan Discrete Wavelet Transform (DWT) dan Support Vector Machine (SVM), diperoleh hasil klasifikasi untuk jantung sehat, tachycardia, bradycardia, dan first degree heart block.

Adaptive Neuro Fuzzy Inference System (ANFIS) adalah hasil perpaduan dari jaringan saraf tiruan dan logika fuzzy. Pada sistem berbasis aturan linguistik, teknik jaringan saraf tiruan akan memberikan kemampuan pembelajaran dan adaptasi untuk mengekstraksi parameter-parameter (premis dan konsekuen) aturan fuzzy dari sekumpulan data numerik. Pada ANFIS, parameter adalah fungsi keanggotaan premis dan konsekuensi. Pembelajaran ANFIS berfungsi untuk memperbaiki parameter fungsi keanggotaan masukan dan keluaran. ANFIS dapatditerapkan pada masalah klasifikasi, clustering, dan peramalan pada data runtun waktu.

Beberapa penelitian yang telah dilakukan menggunakan ANFIS antara lain, penelitian oleh Deepak dan Mathew (2012) tentang klasifikasi EKG menggunakan ANFIS dan diperoleh akurasi sebesar 93\%. Penelitian oleh 
Holle, dkk (2016) tentang diagnosis penyakit jantung menggunakan ANFIS dengan fungsi keanggotaan yang digunakan adalah Beta dan Gauss, diperoleh tingkat akurasi dengan fungsi keanggotaan Beta sebesar 65,66\% dan dengan fungsi keanggotaan Gauss sebesar $62,63 \%$.

Berdasarkan uraian diatas, akan dilakukan diagnosa untuk penyakit jantung, yaitu normal, left bundle branch block (LBBB), dan right bundle branch block (RBBB) berdasarkan rekaman EKG menggunakan transformasi wavelet dan Adaptive Neuro Fuzzy Inference System (ANFIS).

\section{Metode Penelitian}

\section{Jenis dan Sumber Data}

Data yang digunakan dalam penelitian ini adalah data sekunder, yaitu data hasil pemeriksaan elektrokardiogram (EKG) pasien penyakit jantung yang diperoleh dari physiobank ATM MIT-BIH Arrhythnia Database. Data yang diperoleh terdiri dari 4 data rekaman EKG pasien Normal, 3 data rekaman EKG dengan diagnosa $\mathrm{LBBB}$, dan 3 data rekaman EKG dengan diagnosa RBBB, sehingga data yang diperoleh berjumlah 10 data. Setiap data berdurasi masing-masing 10 detik dan terdiri dari 9-11 gelombang, yang selanjutnya masing-masing data akan dipotong menjadi 10 bagian, sehingga diperoleh 100 data hasil rekaman EKG.

\section{Teknik Analisis Data}

Pada penelitian ini analisis yang digunakan adalah Transformasi Wavelet Diskrit untuk mengekstraksi data sinyal EKG dan Adaptive Neuro Fuzzy Inference System untuk proses klasifikasi penyakit jantung, yaitu normal, LBBB, dan RBBB. Langkahlangkah analisis data sinyal EKG adalah sebagai berikut:

1. Pre-processing data berupa pemotongan data sinyal EKG

2. Melakukan ekstraksi sinyal EKG menggunakan transformasi wavelet. Hasil ekstraksi adalah nilai energi, nilai puncak $\mathrm{P}$, nilai lembah $\mathrm{Q}$, nilai puncak $\mathrm{R}$, nilai lembah $\mathrm{S}$, dan nilai puncak $\mathrm{T}$.

3. Membentuk model ANFIS. Model ANFIS yang digunakan pada penelitian ini adalah model Sugeno orde satu. Proses pembentukan model ANFIS dimulai dengan melakukan pengklasteran data menggunakan algoritma Fuzzy C-Means Clustering (FCM), mencari nilai rata-rata dan deviasi standar 


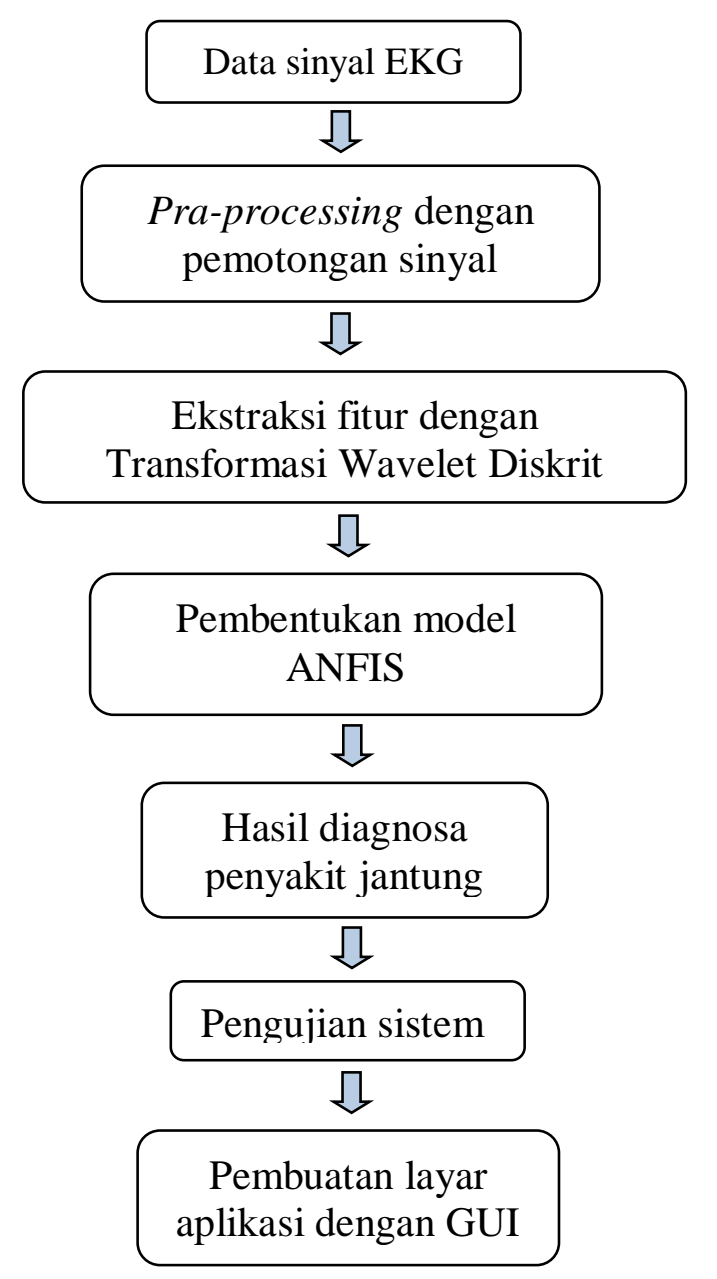

Gambar 1. Bagan Proses Analisis Data

berdasarkan kecenderungan data masuk ke suatu klaster, menghitung output dari lapisan pertama sampai lapisan kelima

4. Melakukan pengujian terhadap data untuk mengetahui akurasi, sensitivitas, dan spesifisitas.

5. Mengkonstruksi hasil dari model dengan Graphcal User Interface (GUI), Hal ini bertujuan untuk memudahkan pembacaan hasil diagnosa dan memberikan tampilan yang lebih menarik.
Gambar 1 menunjukkan bagan proses analisis sinyal EKG menggunakan transformasi wavelet dan ANFIS.

\section{hasil penelitian dan pembahasan}

Data rekaman sinyal EKG yang diperoleh berdurasi 10 detik dan terdiri dari 9-11 gelombang EKG. Proses pemotongan dilakukan untuk memperoleh satu gelombang lengkap EKG yang terdiri dari satu puncak $\mathrm{R}$, satu lembah Q, satu lembah S, satu puncak $\mathrm{P}$, dan satu puncak $\mathrm{T}$ seperti pada Gambar 2.

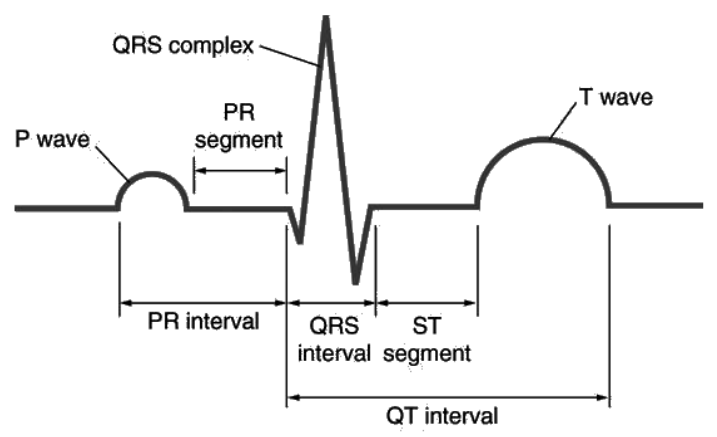

Gambar 2. Satu gelombang EKG Lengkap (Thaler, 2007: 32).

Gambar 3 menunjukkan rekaman EKG sebelum dan setelah dipotong. Hasil pemotongan rekaman sinyal EKG selanjutnya akan didekomposisi dan diekstraksi untuk mendapatkan informasi yang terdapat di dalam sinyal, selain itu proses dekomposisi juga bertujuan untuk menghilangkan derau (noise) yang terdapat pada sinyal. 
Proses dekomposisi menggunakan

transformasi wavelet diskrit dengan

mother coifflet-2 dengan level

maksimum 5.
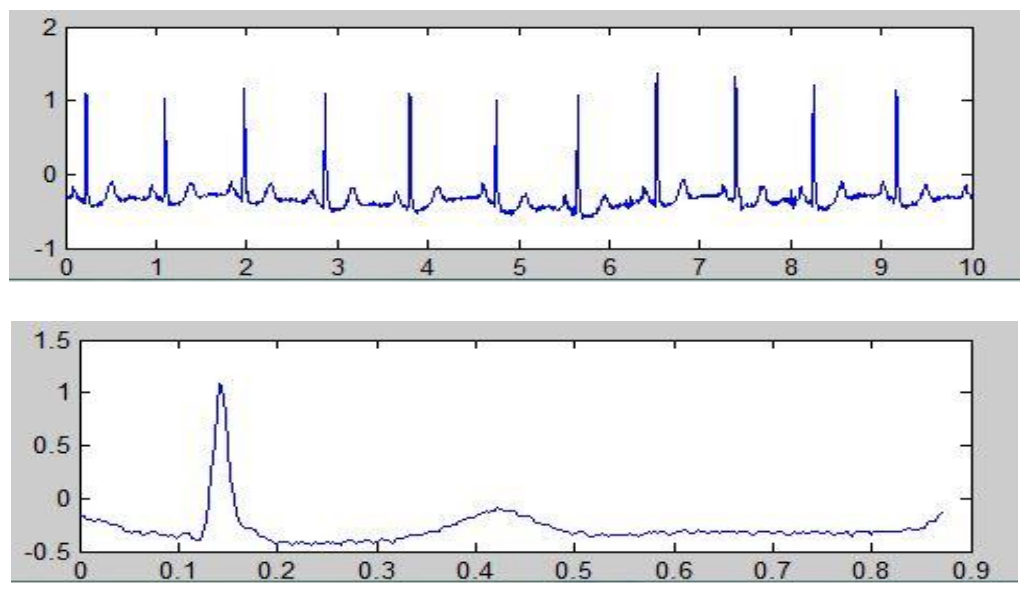

Gambar 3. Rekaman Sinyal EKG ar101.mat sebelum dan setelah dipotong

Nilai energi pada setiap level menentukan hasil dekomposisi pada level ke-berapa yang akan digunakan untuk ekstraksi sinyal EKG. Hasil dekomposisi pada level dengan nilai energi terbesar akan dipilih untuk menghasilkan parameter-parameter yang diperlukan sebagai input untuk proses klasifikasi dengan menggunakan ANFIS. Tabel 1 menunjukkan nilai energi pada level pertama sampai level kelima untuk dekomposisi TWD pada sinyal ar101_1.mat

Tabel 1. Nilai Energi Dekomposisi TWD

\begin{tabular}{cc}
\hline Level & Nilai Energi \\
\hline $\mathrm{d} 1$ & 0.0267 \\
$\mathrm{~d} 2$ & 0.5157 \\
$\mathrm{~d} 3$ & 4.5122 \\
$\mathrm{~d} 4$ & 2.5564 \\
$\mathrm{~d} 5$ & 10.5203 \\
\hline
\end{tabular}

Berdasarkan Tabel 1 dipilih dekomposisi sinyal pada d5 untuk menghasilkan parameter-parameter pada sinyal EKG, seperti tinggi puncak $\mathrm{R}$, puncak $\mathrm{P}$, puncak $\mathrm{T}$, lembah $\mathrm{Q}$ dan lembah S, yang selanjutnya akan digunakan sebagai input pada proses klasifikasi. Hasil dekomposisi sinyal EKG pada level d5 dapat dilihat pada Gambar 4.

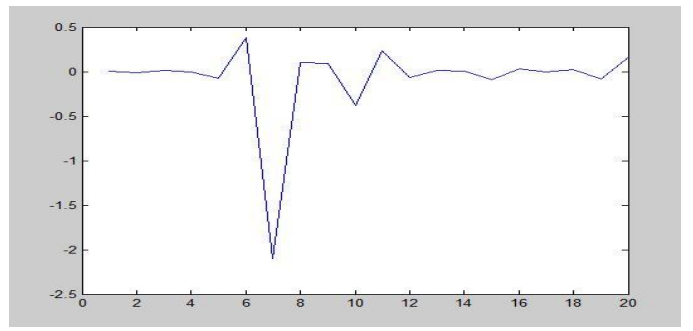

Gambar 4. Sinyal EKG setelah proses dekomposisi pada level d5. 
Tabel 2 menunjukkan informasi mengenai parameter-parameter yang diperoleh dari hasil ekstraksi sinyal ar101_1.mat pada level d5.

Tabel 2. Hasil Ekstraksi Sinyal EKG

\begin{tabular}{ccc}
\hline No & Parameter & Nilai \\
\hline 1 & Puncak R & 0.3796 \\
2 & Lembah Q & -0.0756 \\
3 & Puncak P & 0.0151 \\
4 & Lembah S & -2.0983 \\
5 & Puncak T & 0.2359 \\
6 & Energy & 10.5203 \\
\hline
\end{tabular}

Pendefinisian variabel input dan output.

Proses awal pemodelan ANFIS adalah menentukan variabel input dan output yang akan digunakan sebagai input dan target jaringan. Variabel input diperoleh dari hasil dekomposisi sinyal EKG menggunakan mother wavelet Coiflet-2 level 5, sehingga diperoleh 6 parameter yaitu, puncak $\mathrm{R}$, puncak $\mathrm{P}$, puncak $\mathrm{T}$, lembah $\mathrm{Q}$, lembah $\mathrm{S}$, dan energi yang selanjutnya akan digunakan sebagai variabel input pada model. Variabel output atau target jaringan berupa klasifikasi dari hasil dekomposisi sinyal EKG.

\section{Pembagian Data Input}

Data input yang telah diperoleh dari hasil dekomposisi TWD selanjutnya dibagi menjadi dua, yaitu data latih dan data uji. Data latih akan digunakan untuk pembelajaran jaringan hingga diperoleh model terbaik, sedangkan data uji digunakan untuk uji atau validasi model. Pada penelitian ini digunakan $70 \%$ data atau sebanyak 70 data sebagai data latih dan $30 \%$ data atau 30 data sebagai data uji. Pemilihan data latih dan uji dilakukan secara acak.

\section{Pengelompokan (Clustering) Data}

Pengelompokan atau clustering data latih dan uji dilakukan untuk memperoleh nilai keanggotaan setiap data pada setiap klaster dan kecenderungan suatu data masuk ke suatu klaster tertentu. Pada penelitian ini digunakan algoritma Fuzzy C-Means (FCM) dengan banyaknya klaster yang digunakan adalah 10. Dengan algoritma FCM diperoleh aturan pada ANFIS model Sugeno Orde Satu adalah sebanyak 10 aturan, yaitu sebagai berikut

Aturan (1) Jika Energy adalah $E_{1}$ dan $\mathrm{R}$ adalah $R_{1}$ dan $\mathrm{Q}$ adalah $Q_{1}$ dan $\mathrm{P}$ adalah $P_{1}$ dan $\mathrm{S}$ adalah $S_{1}$ dan $\mathrm{T}$ adalah $T_{1}$ maka $y_{1}=c_{11}$ Energy $+c_{12} R+$ $c_{13} Q+c_{14} P+c_{15} S+c_{16} T+c_{10}$

Aturan (10) Jika Energy adalah $E_{10}$ dan R adalah $R_{10}$ dan $\mathrm{Q}$ adalah $Q_{10}$ dan $\mathrm{P}$ adalah $P_{10}$ dan $\mathrm{S}$ adalah $S_{10}$ dan $\mathrm{T}$ adalah $T_{10}$ maka $y_{1}=c_{101}$ Energy + 
$c_{102} R+c_{103} Q+c_{104} P+c_{105} S+$

$c_{106} T+c_{100}$

\section{Lapisan Pertama}

Output pada lapisan pertama adalah derajat keanggotaan yang diberikan oleh fungsi keanggotaan input. Fungsi keanggotaan yang digunakan adalah Generalized bell membership function (gbellmf) dengan persamaan:

$$
\mu(x)=\frac{1}{1+\left|\frac{x-c}{a}\right|^{2 b}}
$$

dengan $a$ adalah standar deviasi setiap klaster, $c$ adalah pusat atau rata-rata setiap klaster, dan $b=1$. Nilai $c$ dan $a$ diperoleh pada proses pengelompokan (clustering) dengan FCM.

\section{Lapisan Kedua}

Tiap-tiap neuron pada lapisan kedua merupakan neuron tetap yang outputnya adalah hasil dari masukan. Biasanya digunakan operator AND. Tiap-tiap node mempresentasikan $\alpha$-predikat dari aturan ke-i. Output dari lapisan kedua adalah hasil perkalian dari derajat keanggotaan yang diperoleh pada lapisan pertama. Tabel 3 menunjukkan output dari lapisan kedua.

$$
w_{i}=\mu A_{i} \times \mu B_{i}
$$

Tabel 3. Output Lapisan Kedua

\begin{tabular}{ccccc}
\hline$w_{1}$ & $w_{2}$ & $w_{3}$ & $\ldots$ & $w_{10}$ \\
\hline 0.000289 & 0.008289 & $4.28 \mathrm{E}-07$ & $\ldots$ & 0.0275898 \\
0.000695 & 0.090536 & $1.54 \mathrm{E}-06$ & $\ldots$ & 0.0048174 \\
$\vdots$ & $\vdots$ & $\vdots$ & $\vdots$ & $\vdots$ \\
0.187168 & 0.000746 & $1.24 \mathrm{E}-05$ & $\ldots$ & $5.87 \mathrm{E}-08$ \\
\hline
\end{tabular}

\section{Lapisan Ketiga}

Tiap neuron pada lapisan ketiga merupakan hasil perhitungan rasio dari $\alpha$-predikat $(w)$ dari aturan $\mathrm{ke}-i$ terhadap jumlah keseluruhan $\alpha-$ predikat.

$$
\bar{w}_{i}=\frac{w_{i}}{w_{1}+w_{2}+\cdots+w_{10}}, \text { dengan }
$$

Output pada lapisan ketiga disebut dengan normalized firing strength.Tabel 4 menunjukkan output dari lapisan ketiga.

Tabel 4. Output lapisan ketiga

\begin{tabular}{ccccc}
\hline $\bar{w}_{1}$ & $\bar{w}_{2}$ & $\bar{w}_{3}$ & $\cdots$ & $\bar{w}_{10}$ \\
\hline 0.000676 & 0.019419 & $1.00 \mathrm{E}-06$ & $\ldots$ & 0.064637 \\
0.00125 & 0.162737 & $2.76 \mathrm{E}-06$ & $\ldots$ & 0.008659 \\
$\vdots$ & $\vdots$ & $\vdots$ & $\vdots$ & $\vdots$ \\
0.294685 & 0.001174 & $1.95 \mathrm{E}-05$ & $\cdots$ & $9.24 \mathrm{E}-08$ \\
\hline
\end{tabular}

\section{Lapisan Keempat}

Pada lapisan keempat terdapat parameter baru yang disebut parameter konsekuen yang dapat diperoleh dengan menggunakan metode dekomposisi nilai singular. 


$$
\begin{gathered}
\bar{w}_{i} y_{i}=\bar{w}_{i}\left(c_{i 1} x_{1}+c_{i 2} x_{2}+\cdots+\right. \\
\left.c_{i 6} x_{6}+c_{i 0}\right), \text { dengan } i=1,2,3, \ldots, 10 .
\end{gathered}
$$

Penentuan Parameter

Konsekuen dalam model aturan Sugeno orde satu adalah berbentuk persamaan linear sehingga membentuk suatu Sistem Persamaan Linear (SPL). SPL yang dihasilkan memiliki jumlah persamaan yang tidak sama dengan jumlah variabel, sehingga metode dekomposisi nilai singular digunakan untuk mencari penyelesaian SPL tersebut.

\section{1) Membentuk Matriks $X$}

Data latih yang digunakan adalah sebanyak 70 data dengan 6 variabel dan 10 aturan yang terbentuk, maka matriks $X$ yang dihasilkan berukuran $70 \times$ $[(6+1) \times 10]=70 \times 70$.

\section{2) Menentukan Parameter}

Matriks $X$ yang diperoleh berukuran $70 \times 70$ dan semua entrinya adalah bilangan real, maka untuk menentukan parameter pada konsekuen dapat digunakan metode dekomposisi nilai singular, sebagai berikut

$$
A=U \sum \mathrm{V}^{\mathrm{T}}
$$

dengan A adalah matriks $X$ yang terbentuk, $U$ dan $V$ merupakan matriks uniter yang diperoleh berdasarkan nilai singular dari matriks A.. Nilai singular yang diperoleh dinyatakan dalam bentuk grafik dan dapat dilihat pada Gambar 5

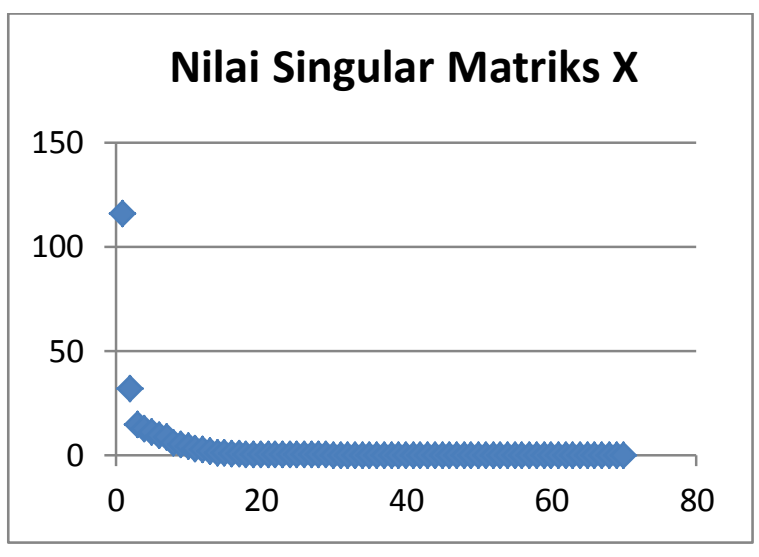

Gambar 5. Grafik Nilai Singular Matriks X

Setelah diperoleh matriks $U, \sum$, dan $V$, dengan menggunakan Persamaan $A=U \sum \mathrm{V}^{\mathrm{T}}$, maka diperoleh pula nilai parameter konsekuen sebagai berikut -3.274046 , $452.2658,317.6008,-0.726246, \ldots .$.

\section{Lapisan kelima}

Lapisan kelima hanya memiliki satu simpul output yang merupakan keluaran atau hasil dari seluruh perhitungan yang telah dilakukan pada lapisan sebelumnya. Nilai output pada lapisan kelima diperoleh dengan menggunakan persamaan berikut

$$
\begin{aligned}
y=\left(\bar{w}_{1} x_{1}\right) c_{11}+ & \left(\bar{w}_{1} x_{2}\right) c_{12}+\cdots+\bar{w}_{1} c_{10} \\
& +\left(\bar{w}_{2} x_{1}\right) c_{21}+\cdots+\bar{w}_{2} c_{20} \\
& +\cdots \\
& +\left(\bar{w}_{10} x_{1}\right) c_{101}+\ldots+\bar{w}_{10} c_{100}
\end{aligned}
$$

dimana nilai $\bar{w}_{i}$ diperoleh pada lapisan ketiga dan koefisien $c_{i j}$ atau yang 
disebut dengan parameter konsekuen diperoleh pada lapisan keempat. Tabel 5 menunjukkan hasil output pada lapisan kelima.

Tabel 5.Output ANFIS untuk data latih

\begin{tabular}{ccc}
\hline No & $\begin{array}{c}\text { Target } \\
\text { Output }\end{array}$ & $\begin{array}{c}\text { Output } \\
\text { Jaringan }\end{array}$ \\
\hline 1. & 0 & $1.5890 \mathrm{E}-12$ \\
2. & 0 & $-2.5984 \mathrm{E}-12$ \\
$\ldots$ & $\ldots$ & $\ldots$ \\
70. & 2 & 1.999999995 \\
\hline
\end{tabular}

\section{Uji Ketepatan Model untuk Diagnosis}

Model yang telah dibangun pada latih selanjutnya akan diujikan pada seluruh data, baik data latihmaupun data uji. Hal ini dilakukan untuk mengetahui tingkat ketepatan model yang dibangun. Hasil output jaringan untuk 70 data latihdengan jumlah $T P=42, T N=$ 28, $F P=0, \quad$ dan $F N=0, \quad$ sehingga diperoleh nilai akurasi, sensivitas, dan spesifitas pada data latih sebagai berikut

$$
\begin{aligned}
& \text { akurasi }=\frac{\text { banyak data benar }}{\text { banyak data keseluruhan }} \\
& \times 100 \%=\frac{70}{70} \times 100 \% \\
& =100 \% \\
& \text { sensitivitas }=\frac{T P}{T P+F N} \times 100 \% \\
& =\frac{42}{42} \times 100 \%=100 \% \text {. } \\
& \text { spesifisitas }=\frac{T N}{T N+F P} \times 100 \% \\
& =\frac{28}{28} \times 100 \%=100 \% \text {. }
\end{aligned}
$$

Pada 30 data uji diperoleh jumlah $T P=18, T N=12, F P=0, \operatorname{dan} F N=$
0, sehingga diperoleh nilai akurasi, sensitivitas, dan spesifitas pada data uji sebagai berikut

$$
\begin{aligned}
& \text { akurasi }=\frac{\text { banyak data benar }}{\text { banyak data keseluruhan }} \\
& \times 100 \%=\frac{30}{30} \times 100 \% \\
& \text { sensitivitas }=\frac{T P}{T P+F N} \times 100 \% \\
& =\frac{18}{18} \times 100 \%=100 \% \text {. } \\
& \text { spesifisitas }=\frac{T N}{T N+F P} \times 100 \% \\
& =\frac{12}{12} \times 100 \%=100 \% \text {. }
\end{aligned}
$$

Tampilan Diagnosa Penyakit Jantung dengan Graphical User Interface (GUI)

Model diagnosa penyakit jantung yang telah dibangun dengan menggunakan metode ANFIS, selanjutnya dikonstruksi dengan GUI sehingga memudahkan data untuk dibaca dan menghasilkan tampilan lebih menarik. Tampilan GUI untuk model diagnosa penyakit jantung ditunjukkan pada gambar 6 .

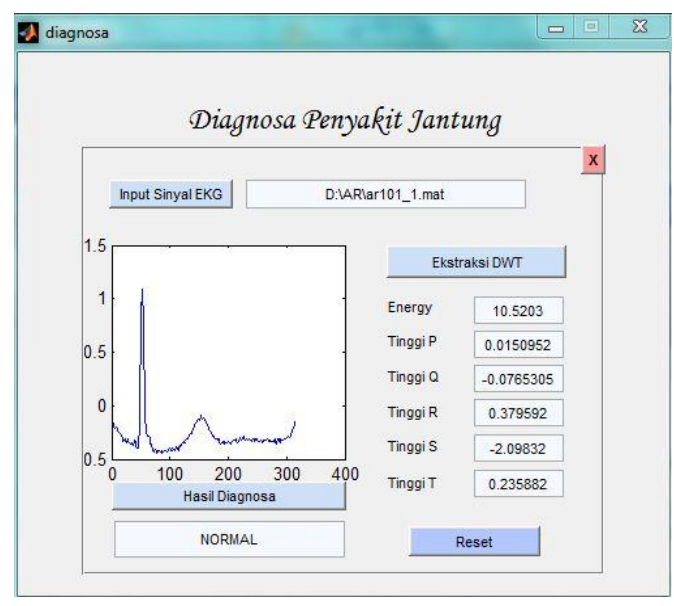

Gambar 6. Tampilan GUI untuk Diagnosa Penyakit Jantung 
Rancangan GUI pada Gambar 6 menggunakan data latih dengan diagnosa awal adalah normal. Sinyal EKG yang telah dipotong, selanjutnya disimpan dalam file berekstensi *.mat. File tersebut kemudian dimasukkan ke dalam rancangan GUI yang telah dibuat dan diekstraksi menggunakan Transformasi Wavelet Diskrit (TWD). Hasil ekstraksi dengan TWD menghasilkan 6 buah parameter yang dijadikan input pada model ANFIS yang telah dibangun. Setelah diproses dengan model yang telah dibangun, diperoleh bahwa sinyal tersebut merupakan sinyal EKG normal..

\section{Kesimpulan}

Ekstraksi sinyal EKG dengan Transformasi Wavelet Diskrit (TWD) menghasilkan 6 parameter, yaitu energi, tinggi puncak $\mathrm{P}$, puncak $\mathrm{R}$, puncak $\mathrm{T}$, lembah Q, dan lembah S.

Model ANFIS terbaik dengan 10 klaster. Tingkat akurasi pada data latih mencapai $100 \%$, spesifisitas $100 \%$ dan sensitivitas $100 \%$, begitu pula pada data uji dimana tingkat akurasi, spesifisitas, dan sensitivitas masing-masing mencapai $100 \%$, 100\%, dan $100 \%$.

\section{Saran}

Menggunakan data rekaman EKG yang diperoleh secara langsung dari rumah sakit dan mempertimbangkan kondisi pasien, seperti usia, berat badan, riwayat penyakit, dan kondisi lainnya, sehingga hasil yang diperoleh lebih akurat dan sesuai dengan diagnosa dari pihak medis rumah sakit

Menggunakan mother wavelet yang lainnya, seperti Haar, Daubechies, dan Symlets pada proses ekstraksi dengan TWD, sehingga dapat digunakan sebagai perbandingan untuk memperoleh model terbaik.

\section{Daftar Pustaka}

Deepak, N. \& Mathew, A. (2012). Adaptive neuro fuzzy inference system classification of ecg signal. International Journal of Advanced Research in Electrical, Electronics and Instrumentation Engineering Vol.1, Issue , 70-76.

Dharma, Surya. (2009). Pedoman praktis sistematika interpretasi ekg. Jakarta: Penerbit Buku Kedokteran.

Holle, K.F.H., Ludviani, R., Cahyani, L. (2016). Diagnosis penyakit jantung menggunakan adaptive neuro fuzzy inference system (ANFIS). MATICS: Jurnal Ilmu Komputer dan Teknologi Informasi, Vol. 8, No. 21, 44-47.

Kemenkes RI. (2014). Info DATIN situasi kesehatan jantung. Jakarta Selatan: Kemenkes RI 
PhysioNet. Diakses dari PhysioBank ATM

https://www.physionet.org/cgi-

bin/atm/ATM pada tanggal 20

Februari 2018 pukul 20.36 WIB

Thaler, M. S. (2007). The only EKG book you'll ever need ( $5^{\text {th }}$ ed). Lippincott Williams \& Wilkins.

Vijayavanan, M., Rathikarani, V., Dhanalakshmi, P. (2014). Automatic classification of ECG signal for heart disease diagnosis using morphological features. International Journal of Computer Science \& Engineering Technology (IJCSET) Vol.5 No.04, 449-455.

Zadawale, S. S. \& Bakare, S. (2017). ECG signal based heart disease prediction system using DWT and SVM. International Journal of Advanced Research in Computer and Communicatinon Engineering ISO 3297: 2007 Certified, 61-66. 